\title{
ADMINISTRASI PUBLIKASI ONLINE MGMP SMK MALANG
}

\author{
Yusriel Ardian ${ }^{1}$, Kawakibul Qamar $^{2}$ \\ ${ }^{1,2}$ Program Studi Sistem Informasi, ${ }^{1,2}$ Fakultas Sains dan Teknologi, \\ ${ }^{1,2}$ Universitas Kanjuruhan Malang \\ 1,2 yusriel@unikama.ac.id
}

\begin{abstract}
ABSTRAK
Pengembangan Keprofesian Berkelanjutan (PKB) adalah konsekuensi dari guru sebagai profesi. Guru sebagai profesi mempunyai fungsi, peran, dan kedudukan yang sangat penting dalam menciptakan insan Indonesia cerdas dan kompetitif. Masih terlihat adanya kelemahan dari guru untuk melakukan publikasi ilmiah, yang disebabkan kurangnya keterampilan guru-guru untuk dalam mengelola artikel ilmiah sebagai hasil dari tulisan karya tulis ilmiah. Untuk itu diperlukan usaha untuk meningkatkan keterampilan guru yang dikolaborasikan dengan pengembangan diri dan karya inovatif sebagai bagian PKB dengan indikasi sudah dilaksanakan dengan baik. Permasalahan yang dihadapi guru di sekolah adalah: (a) Keterampilan guru untuk menjadi operator masih rendah, (b) Kegiatan peningkatan kompetensi di sekolah tidak menyentuh aspek keterampilan komputer sebagai bagian dari administrator publikasi online, (c) Dana kegiatan masih mengacu pada hal administratif sehingga kegiatan sangat sulit dilakukan, (d) Kesulitan dalam mendatangkan pihak kompeten untuk meningkatkan kompetensi administrasi publikasi online karena keterbatasan pengetahuan dan relasi terhadap instruktur. Hasil dari kegiatan pengabdian ini adalah (a) kesiapan dalam mempublikasikan artikel karya tulis ilmiah, (b) Handout yang dapat diimbaskan kepada guru lain, (c) Pendampingan selama kurang lebih 3 bulan
\end{abstract}

Kata-kata kunci : pelatihan, administrasi jurnal, online

\section{ABSTRACT}

Sustainable Professional Development is a consequence of the teacher as a profession. Teachers as professions have functions, roles, and positions that are very important in creating Indonesia human beings smart and competitive. There is still a weakness of teachers to conduct scientific publications, due to the lack of skills of teachers to in managing scientific articles as a result of scientific papers writing. Therefore, efforts are needed to improve the skills of teachers collaborated with self-development and innovative work as part of PKB with good indication already implemented. The problems faced by teachers in schools are: (a) Teacher's skills to become operators are still low, (b) Competence improvement activities in schools do not touch aspects of computer skills as part of the administrator of online publications, (c) Activity funds still refer to administrative matters so activities are extremely difficult, $(d)$ Difficulty in bringing in a competent person to improve the competence of the administration of online publications due to the limited knowledge and relationships to the instructor. The results of this devotional activity are (a) readiness in publishing articles of scientific writing, (b) Handouts that may be directed to other teachers, (c) Mentoring for approximately 3 months

Keywords : training, journal administration, online

I. PENDAHULUAN

1.1 Analisis Situasi
Pengembangan Keprofesian Berkelanjutan (PKB) adalah konsekuensi dari guru sebagai profesi berdasarkan 
Peraturan Menteri Negara Pemberdayaan Aparatur Negara dan Reformasi Birokrasi Nomor 16 Tahun 2009 tentang jabatan fungsional guru dan angka kreditnya. Guru sebagai profesi mempunyai fungsi, peran, dan kedudukan yang sangat penting dalam menciptakan insan Indonesia cerdas dan komptetitif, sebagaimana diamanatkan dalam Undang-undang nomor 14 tahun 2005 tentang guru dan dosen.

Dalam melaksanakan PKB, seorang guru akan melakukan tiga hal, yakni:

1. Pengembangan Diri

a. Mengikuti Diklat fungsional

b. Melaksanakan kegiatan kolektif guru

2. Publikasi Ilmiah

a. Membuat publikasi ilmiah atas hasil penelitian

b. Membuat publikasi buku

3. Karya inovatif

a. Menemukan teknologi tepat guna

b. Menemukan/meciptakan karya seni

c. Membuat/memodifikasi alat pelajaran

d. Mengikuti pengembangan, penyusunan, standar, pedoman, soal dan sejenisnya.

Berdasarkan wawancara dengan beberapa guru yang tergabung dalam Musyawarah Guru Mata Pelajaran (MGMP) Matematika SMK Kota Malang, yakni SMK Negeri 3 dan SMK Negeri 12 diperoleh informasi bahwa kesulitan yang terbesar adalah mempublikasikan artikel ilmiah. Kesulitan ini merupakan kelemahan dari guru yang disebabkan kurangnya keterampilan guru-guru untuk dalam mengelola artikel ilmiah sebagai hasil dari tulisan karya tulis ilmiah.
Kelemahan tersebut perlu diselesaikan dengan segera agar PKB dalam dilaksanakan dengan baik. Untuk itu diperlukan usaha untuk mendapatkan solusi dalam mempublikasikan artikel secara mandiri. Publikasi secara mandiri telah dapat dilakukan dengan melalui publikasi online dalam hal ini membuat jurnal online yang lebih diterima di era digital ini. Untuk itu, beberapa guru bersedia untuk menjadi operator untuk mengadministrasi publikasi online ini. Adapun informasi dari hasil diskusi dengan guru MGMP di sekolah diperoleh bahwa guru sudah memiliki bersedia untuk meningkatkan keterampilan diri sesuai dengan program-program yang dijalankan oleh MGMP yakni publikasi artikel secara online.

Salah satu program dari MGMP yang dianggap sebagai solusi dari permasalahan tersebut adalah kegiatan training. Training tersebut dirancang untuk dilakukan oleh para anggota MGMP dengan tujuan peningkatan keterampilan guru dalam hal ini menjadi operator administrasi publikasi online.

\subsection{Permasalahan Mitra}

Permasalahan yang dihadapi guru di sekolah adalah:

a. Keterampilan guru untuk menjadi operator masih rendah

b. Kegiatan peningkatan kompetensi di sekolah tidak menyentuh aspek keterampilan komputer sebagai bagian administrator publikasi online.

c. Dana kegiatan masih mengacu pada hal administratif sehingga kegiatan sangat sulit dilakukan. 
d. Kesulitan dalam mendatangkan pihak kompeten untuk meningkatkan kompetensi administrasi publikasi online karena keterbatasan pengetahuan dan relasi terhadap instruktur.

\section{METODE KEGIATAN}

Kegiatan yang ditawarkan adalah pelatihan selama satu minggu dengan rincian kegiatan pelatihan meliputi teori, praktik dan presentasi.

Sesuai dengan rencana kegiatan pelatihan, berikut diuraikan langkahlangkah pelaksanaan kegiatan pelatihan.

a. Menentukan gaya selingkung suatu artikel

b. Merekrut Mitra Bestari dalam kelayakan artikel

c. Pengenalan Content Management System (CMS)

d. Layout dan Administrator CMS

e. Melakukan analisis kebutuhan CMS

f. Praktik Instalasi CMS

g. Praktik Administrasi CMS

h. Praktik Review Artikel berdasarkan gaya selingkung

i. Praktik Publikasi Online

j. Uji coba presentasi administrasi setiap peserta

k. Evaluasi dari presentasi setiap peserta

Partisipasi Mitra dalam Pelaksanaan Program merupakan hal yang penting untuk keberhasilan program pelatihan ini. Partisipasi mitra yang diharapkan saat pelaksanaan pelatihan ini adalah:

a. Peserta memiliki permasalahan atas sebaran bahan ajar yang dimilikinya

b. Peserta merupakan guru sekolah yang memiliki kesungguhan dan keaktifan serta kooperatif terhadap materi yang disampaikan

c. Pihak sekolah sebagai mitra dalam pelatihan ini menyediakan sarana dan prasarana seperti koneksi internet, ruang, LCD dan proyektor.

\section{HASIL DAN PEMBAHASAN}

Pada bulan Maret 2017, pengabdi memulai menemui ketua MGMP Matematika kota Malang yaitu bapak Drs. Roni Laksana, untuk mendapatkan mitra yang sesuai dengan kebutuhan guru. Ketua MGMP memberikan saran agar menemui perwakilan SMKN 1 Malang serta SMKN 12 Malang. Dari hasil pertemuan ditentukan bahwa kegiatan akan dilaksanakan di SMKN 12 Malang. Pelaksanaan kegiatan pada pihak mitra adalah pelatihan selama satu minggu dengan rincian kegiatan pelatihan meliputi teori, praktik dan presentasi.

Pengabdi memulai menyusun handout yang akan digunakan dalam pelatihan di awal bulan April 2017. Mahasiswa terlibat dalam penyusunan handout ini sehingga membantu dalam mendapatkan konten materi serta layoutnya. Kegiatan workshop dilaksanakan mulai tanggal 9 Mei 2017 sampai dengan 11 Mei 2017. Adapun peserta uang mengikuti workshop berjumlah 18 peserta. Sesuai dengan rencana kegiatan pelatihan, langkahlangkah pelaksanaan kegiatan seperti berikut.

1) Kegiatan tanggal 9 Mei 2017,

a) Menentukan gaya selingkung suatu artikel.

b) Merekrut Mitra Bestari dalam kelayakan artikel 
c) Pengenalan Content Management System (CMS)

2) Kegiatan tanggal 10 Mei 2017 ,

a) Layout dan Administrator CMS

b) Melakukan analisis kebutuhan CMS

c) Praktik Instalasi CMS

3) Kegiatan tanggal 11 Mei 2017,

a) Praktik Administrasi CMS

b) Praktik Review Artikel berdasarkan gaya selingkung

c) Praktik Publikasi Online

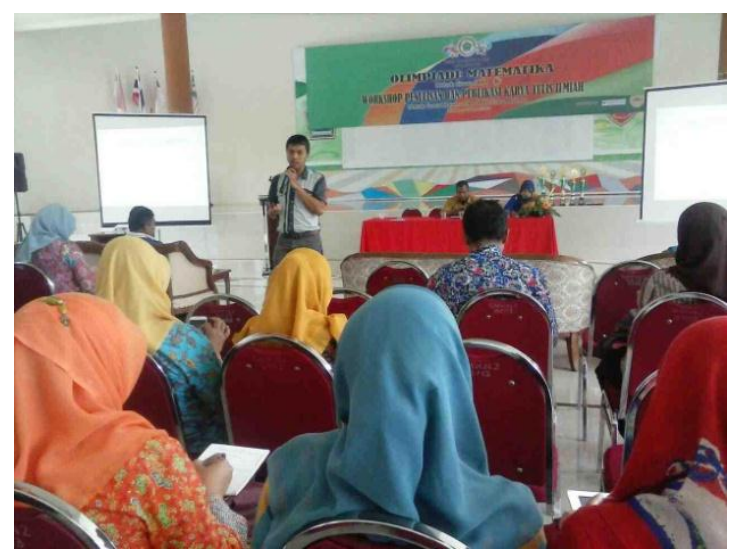

Gambar 5.1 Pelatihan hari pertama

Hasil evaluasi di akhir diperoleh bahwa para peserta memiliki kecepatan dalam melakukan pengembangan dalam administrasi jurnal. Namun, karena masih berfokus pada artikel yang masih berupa template, masih perlu untuk dilakukan pendampingan kepada setiap peserta untuk dapat melakukan administrasi pengelolaan artikel dari penelitian guru yang sedang dilakukan. Pendampingan ini bertujuan agar peserta dapat secara langsung mengelola administrasi jurnal yang siap untuk dipublikasikan. Pendampingan dilaksanakan sekitar bulan Juni sampai bulan Agustus 2017.

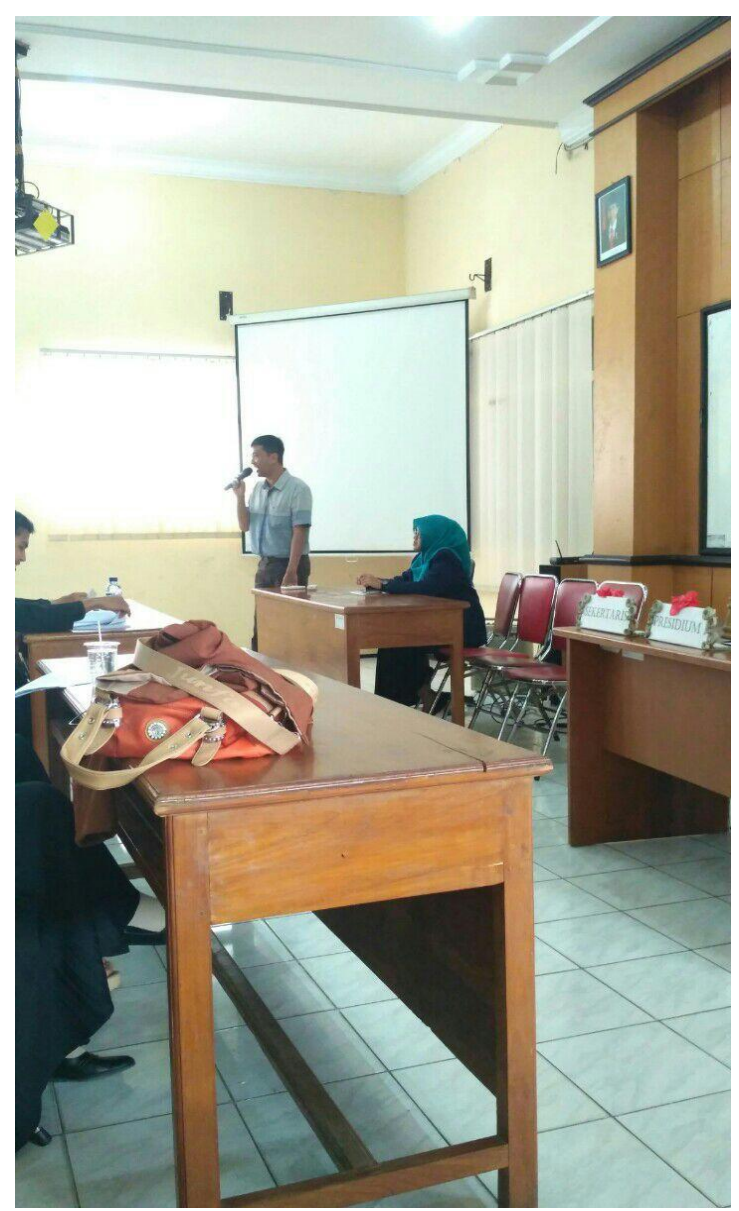

Gambar 5.2 Workshop hari kedua

\section{KESIMPULAN}

Pengabdian pada masyarakat dengan kegiatan pelatihan administrasi jurnal pada MGMP SMK Malang adalah (a) kesiapan dalam mempublikasikan artikel karya tulis ilmiah, (b) Handout yang dapat diimbaskan kepada guru lain, (c) Pendampingan selama kurang lebih 3 bulan (Juni, Juli dan Agustus 2017) untuk menjadi pengelola jurnal yang terpercaya. 
Jurnal Aplikasi Sains dan Teknologi - JAST, Volume 1, Nomor 2, Juli-Desember 2017, e-ISSN 2548-7981

\section{DAFTAR PUSTAKA}

[1] Republik Indonesia. 2005. Undang Undang Nomor 14 Tahun 2005 tentang Guru dan Dosen. Jakarta: Sekretariat Negara
[2] Menteri Negara Pemberdayaan Aparatur Negara dan Reformasi Birokrasi. 2009. Peraturan Menteri Nomor 16 Tahun 2009 tentang Jabatan Fungsional Guru dan Angka Kreditnya. Jakarta: Kemenpan 